Original

\title{
Associations of clinical characteristics and interval between maintenance visits with peri-implant pathology
}

\author{
Miguel A. de Araújo Nobre',2), Paulo S. Maló2), and Sílvia H. Oliveira²) \\ 1)Preventive Medicine Unit, Faculty of Medicine, University of Lisbon, Lisbon, Portugal \\ 2)Malo Clinic, Lisbon, Portugal
}

(Received January 7, 2014; Accepted April 21, 2014)

\begin{abstract}
We investigated the effects of clinical characteristics and the interval between maintenance visits on incidence of peri-implant pathology in a sample of 1,350 patients treated with dental implants (270 cases of peri-implant pathology and 1,080 healthy controls). The chi-square test was used to evaluate differences between cases and controls in the presence of dental plaque, bleeding, peri-implant pockets $>4 \mathrm{~mm}$, bone level, and interval between maintenance visits (significance level, 5\%). Crude odds ratios (ORs) and attributable fractions were calculated for variables that significantly differed between cases and controls. The variables identified as risk indicators were dental plaque $(P<0.001$; OR $=5.2)$, bleeding $(P<0.001 ; \mathrm{OR}=5.0)$, peri-implant pockets $>4 \mathrm{~mm}(P<0.001 ; \mathrm{OR}=17.2)$, bone level $(P$ $<0.001$; middle third, $O R=8.4$; apical third, $O R=$ 8.6), and interval between maintenance visits $(P<$ $0.001 ; 1-3$ months, $O R=2.9 ; 3-5$ months, $O R=2.1)$. Attributable fractions revealed a potential reduction in peri-implant pathology of 53-94\% after removing exposures to dental plaque (81\%), bleeding $(80 \%)$, peri-implant pockets $>4 \mathrm{~mm}(94 \%)$, bone level $(88 \%)$, and interval between maintenance visits (53-66\%). Selected clinical characteristics and the interval between maintenance visits were significantly associated with the incidence of peri-implant pathology.
\end{abstract} (J Oral Sci 56, 143-150, 2014)

Correspondence to Dr. Miguel de Araújo Nobre, Malo Clinic, Avenida dos Combatentes, 43, Andar 5 A, 1600-042, Lisbon, Portugal

Fax: +351-217-266-965

E-mail: miguelnobre@fm.ul.pt \& mnobre@maloclinics.com

doi.org/10.2334/josnusd.56.143

DN/JST.JSTAGE/josnusd/56.143
Keywords: peri-implant pathology; dental implants; risk indicators; dental plaque; bleeding; periimplant pockets.

\section{Introduction}

Peri-implant pathology is a term used to describe "inflammatory reactions with loss of supporting bone tissue surrounding the dental implant" (1). Its pathogenesis has been classified as classical (soft tissue apical to the bone) and retrograde (bone to soft tissue). The classical pathway of peri-implant pathology is caused by exposure to dental plaque (DP) and subsequent reversible mucositis, which can result in bone loss and, ultimately, implant loss $(2,3)$. In the retrograde pathway, bone loss occurs at the bone crest and results from microfractures caused by overloading, premature loading, or lateral forces (4-6). These pathways sometimes overlap (7). The reported prevalence of peri-implant pathology ranges from $12-43 \%$ (8). However, only a few studies have focused on the pathology and risk factors for periimplant pathology (9-20).

Several clinical characteristics are evaluated in an implant maintenance follow-up examination: bone level (BL) near the implant, peri-implant pockets, DP, and the condition of the superficial peri-implant complex, as assessed by means of the modified bleeding index (21) (which differs from bleeding on probing). Maintenance of adequate bone is vital for implant health and is regularly assessed in evaluations of dental implant systems. In the most widely used criterion for evaluating implant success, Albrektsson et al. (22) proposed that implants were successful if average marginal bone resorption after the first year of function was $<0.2 \mathrm{~mm}$ annually. However, this criterion has been questioned by several 
authors, principally due to uncertainty as to whether annual bone loss could be clearly ascertained. This reservation was supported by the results of clinical studies, which found that bone resorption greater than the above limit stabilized after 2-3 years. This evidence led to a recommendation that implants should only be considered failed when BL reached the apical third of the implant (23-25). The findings of a biomechanical study indicated that stability diminished as BL reached the apical third of the implant (26), as did the capacity to support occlusal forces. These biomechanical factors increased the risk of peri-implant pathology. Nevertheless, diminished BL is not always indicative of a pathological condition (22). It might instead be caused by impaired conditions at the implant site at the time of treatment, to implant length, or to physiologically marginal bone remodeling.

The research community continues to debate the usefulness of probing the peri-implant sulcus/pocket. Some view such assessment as a highly sensitive diagnostic tool for monitoring peri-implant conditions (27). Others regard it with some distrust because of the large number of variables that influence such measurement, such as probing force and angulation, probe tip diameter, roughness of the implant and root surface, the inflammatory state of the periodontium, the firmness of marginal tissues, and access limitations (28).

The issue of probing force is particularly important in the measurement of peri-implant pocket depth, as this procedure is more sensitive to variations in force $(27,29)$. Absolute values for probing pocket depth should thus be interpreted with caution, due to variability in surgical implant positioning, e.g., the context of a submucosal implant placement in an esthetic anterior region differs from that of a conventional implant placement in a posterior non-esthetic region (28).

It is important to establish a baseline value for probing pocket depth, as a peri-implant sulcus may develop until a pocket is formed as a result of inflammation. Thus, an increase from baseline probing pocket depth values should be seen as a sign of peri-implant pathology $(30,31)$. The microbiological environments of periimplant pockets and periodontal pockets are comparable, as both facilitate colonization by gram-negative bacteria (32). However, some conditions mimic peri-implant pockets but are not evidence of pathological conditions (pseudopockets). These conditions are caused by a thicker mucosal biotype or loss of the osseous scallop at the interproximal aspect of the implant, in conjunction with the presence of a gingival scallop maintained by bone support from adjacent teeth (33). Furthermore, pocket probing alone is not sufficient to differentiate mucositis from peri-implant pathology (34).

Bleeding at the peri-implant complex (as assessed by the modified bleeding index) (21) can be evaluated during assessment of superficial peri-implant conditions and can be used as an alternative to bleeding on probing (35). Indeed, some researchers believe this method to be the best technique for examining the health of peri-implant mucosa (21). Although this assessment technique permits differentiation between healthy and unhealthy tissues, it cannot identify incipient implant failure and its usefulness is limited in smokers (35).

Potentially periodontopathogenic bacteria can colonize implants soon after insertion (36), and accumulation of DP induces an inflammatory response (37) characterized by inflammation signs such as edema, redness of soft tissue, and bleeding on probing, as confirmed in animal and human studies $(38,39)$. Oral hygiene has a substantial impact on bone stability around osseointegrated implants, even in edentulous patients, and deficient oral hygiene is associated with greater bone resorption (40).

A maintenance protocol is important for implantsupported restorations. An effective preventive regimen allows for maintenance of the health of peri-implant tissues and rapid intervention after diagnosis of a pathological condition (41). Maintenance is necessary for long-term implant success and in the prevention and early diagnosis of peri-implant pathology (42-44). Kourtis et al. (45) highlighted the necessity of a strict recall program for patients treated with implants.

We investigated the associations of clinical characteristics and the interval between maintenance visits (IMV) with incidence of peri-implant pathology.

\section{Materials and Methods}

This report complies with the STROBE (strengthening the reporting of observational studies in epidemiology) guidelines (46). The study was approved by the National Commission of Data Protection (Portugal) and the Ethical Board of the Faculty of Medicine of the University of Lisbon (1976/2009).

This study is a complement to a series of studies on risk factors for peri-implant pathology (20). The study population was men and women who underwent fixed prosthetic reconstruction supported by dental implants (Nobel Biocare AB, Gothenburg, Sweden) at a private clinic (Malo Clinic) in Lisbon, Portugal. To investigate the effects of clinical variables on the incidence of periimplant pathology, this matched case-control study used a hospital-based methodology (patients were selected from the same population treated at a private practice).

The cases were patients who were treated with fixed 
prosthetic implant-supported prostheses and later developed peri-implant pathology. The controls were patients who received fixed prosthetic implant-supported prostheses at the same private clinic but did not develop chronic peri-implant pathology.

Peri-implant pathology was defined as the presence of peri-implant pockets $\geq 5 \mathrm{~mm}$, as determined using a plastic periodontal probe calibrated to $0.25 \mathrm{~N}$ (ClickProbe, KerrHawe S. A., Bioggio Svizzera, Switzerland) (47); bleeding on probing (47); bone loss on periapical radiographs (32); and clinical attachment loss $\geq 2 \mathrm{~mm}$ (48).

To be included in the study, the patients had to be treated and followed for at least 1 year at the private clinic and to have provided informed consent for participation and review of their medical charts.

Patients were excluded from the study if they were younger than 18 years, if they declined or were unable to provide informed consent, if they had been followedup for less than 1 year, if their medical records were incomplete or missing, or if they were receiving immunosuppressive therapy.

Data collection took place from January through July 2009. The control patients were matched to cases for sex (19), age ( \pm 2 years) (49), and duration of follow-up ( \pm 2 months). The decision to match for these variables was based on the possibility of a correlation between increased duration of follow-up (corresponding to increased exposure time) and incidence of peri-implant pathology (50). A case: control ratio of 1:4 was established to optimize the number of available cases.

From among an initial 1,763 eligible adults (346 cases; 1,417 controls) retrieved from a list of patients treated with implants, 383 patients (66 cases and 317 controls) were excluded from the study: 202 (54 cases and 148 controls) declined to participate and 181 (12 cases and 169 controls) had incomplete medical records that did not permit accurate diagnosis. Thirty patients (10 cases and 20 controls) were randomly selected for a pilot study to test procedures for data collection and analysis and were excluded from the present study. Ultimately, a sample of 1,350 patients ( 270 cases and 1,080 controls) of both sexes was evaluated. The age range of the sample was 28-88 years (average [SD], 55.8 [10.2] years); 62.7\% of the patients were women. In total, 566 patients (102 cases and 464 controls) presented with systemic compromise, and 364 patients (104 cases and 260 controls) were smokers. The patients were treated with dental implants (296 machined-surface implants and 1,054 implants with a moderately rough surface; Nobel Biocare $\mathrm{AB}$ ) during the period from February 1998 through November 2006.
Peri-implant pathology was diagnosed after an average follow-up time of 3 years.

Data were collected by means of indirect documentation using a digital form, after consulting patient records. The variables evaluated in cases and controls were DP (presence, absence), bleeding (B) at the peri-implant complex (presence, absence); peri-implant pockets (PIP) $>4 \mathrm{~mm}$ (present, absent); BL (coronal, middle, or apical third of implants); IMV during the previous year (1-3 months, 4-5 months, 6 months, $>6$ months).

\section{Statistical analysis}

Using descriptive statistics, we characterized cases and controls with regard to the variables of interest. Inferential statistics were used to evaluate differences in the distributions of variables between cases and controls. For nominal independent variables, the chi-square test was used when appropriate, otherwise the Fisher exact test was used in conjunction with supplemental measurement of Cramer's V statistic or the contingency coefficient. The effect of independent variables that were significant in the analysis was estimated using crude odds ratios (ORs) with $95 \%$ confidence intervals (CIs).

The percentage of cases that could be prevented by removing the exposure to a risk indicator was estimated using the attributable fraction (AF) equation (51) according to the OR for the exposure, as follows:

$$
\mathrm{AF}=\frac{A 1+}{M 1+} \frac{O R-1}{O R}
$$

where AF corresponds to the attributable fraction, $\mathrm{A} 1+$ represents disease prevalence among exposed individuals, and M1+ represents disease prevalence (20).

\section{Results}

The descriptive statistics are shown in Tables 1a-1c. Most cases and controls had no DP or B when evaluated (Table 1a). The percentage of implants with PIP $>4$ $\mathrm{mm}$ was $9.3 \%$, while BL was usually at the coronal third of implants $(88.4 \%)$ (Table 1b). The IMV during the previous year was $>6$ months in most patients (Table 1c).

All investigated variables - namely, DP, B, PIP >4 $\mathrm{mm}, \mathrm{BL}$, and $\mathrm{FVM}$ - significantly differed between cases and controls $(P<0.001$ for all comparisons) (Table $2)$. The proportions of smokers among cases $(38.5 \%)$ and controls $(24 \%)$ also significantly differed (difference, $14 \% ; P<0.001)$.

DP, B, PIP $>4 \mathrm{~mm}$, and BL around the middle or apical third of the implant were risk indicators for the incidence of peri-implant pathology. The OR for peri-implant pathology associated with PIP $>4 \mathrm{~mm}$ was 17.21 , and DP and B were associated with ORs for peri-implant 
Table 1a Presence of dental plaque and bleeding in cases and controls

\begin{tabular}{|c|c|c|c|c|c|c|c|}
\hline & & \multicolumn{3}{|c|}{ Dental plaque } & \multicolumn{3}{|c|}{ Bleeding } \\
\hline & & Absent & Present & Total & Absent & Present & Total \\
\hline Cases, & No. & 197 & 73 & 270 & 200 & 70 & 270 \\
\hline \multicolumn{2}{|c|}{$\%$ of cases } & $73.0 \%$ & $27 \%$ & $100 \%$ & $74.1 \%$ & $25.9 \%$ & $100 \%$ \\
\hline \multicolumn{2}{|c|}{$\%$ of total sample } & $14.6 \%$ & $5.4 \%$ & $20 \%$ & $14.8 \%$ & $5.2 \%$ & $20 \%$ \\
\hline Controls & No. & 1,008 & 72 & 1,080 & 1,009 & 71 & 1,080 \\
\hline \multicolumn{2}{|c|}{$\%$ of controls } & $93.3 \%$ & $6.7 \%$ & $100 \%$ & $93.4 \%$ & $6.6 \%$ & $100 \%$ \\
\hline \multicolumn{2}{|c|}{$\%$ of total sample } & $74.7 \%$ & $5.3 \%$ & $80 \%$ & $74.7 \%$ & $5.3 \%$ & $80 \%$ \\
\hline Total, & No. & 1,205 & 145 & 1,350 & 1,209 & 141 & 1,350 \\
\hline \multicolumn{2}{|c|}{$\%$ of total sample } & $89.3 \%$ & $10.7 \%$ & $100 \%$ & $89.6 \%$ & $10.4 \%$ & $100 \%$ \\
\hline
\end{tabular}

Table 1b Presence of peri-implant pockets $>4 \mathrm{~mm}$ and bone level around implants in cases and controls

\begin{tabular}{llllllll}
\hline & \multicolumn{3}{c}{ Peri-implant pockets $>4 \mathrm{~mm}$} & \multicolumn{4}{c}{ Bone level } \\
\cline { 2 - 7 } & Absent & Present & Total & $\begin{array}{l}\text { Coronal } \\
\text { third }\end{array}$ & $\begin{array}{l}\text { Middle } \\
\text { third }\end{array}$ & $\begin{array}{l}\text { Apical } \\
\text { third }\end{array}$ & Total \\
\hline Cases, No. & 177 & 93 & 270 & 176 & 85 & 9 & 270 \\
\% of cases & $65.6 \%$ & $34.4 \%$ & $100 \%$ & $65.2 \%$ & $31.5 \%$ & $3.3 \%$ & $100 \%$ \\
\% of total sample & $13.1 \%$ & $6.9 \%$ & $20 \%$ & $13.0 \%$ & $6.3 \%$ & $0.7 \%$ & $20 \%$ \\
Controls, No. & 1,048 & 32 & 1,080 & 1,017 & 56 & 7 & 1,080 \\
\% of controls & $97.0 \%$ & $3.0 \%$ & $100 \%$ & $94.2 \%$ & $5.2 \%$ & $0.6 \%$ & $100 \%$ \\
\% of total sample & $77.6 \%$ & $2.4 \%$ & $80 \%$ & $75.3 \%$ & $4.1 \%$ & $0.5 \%$ & $80 \%$ \\
Total, No. & 1,225 & 125 & 1,350 & 1,193 & 141 & 16 & 1,350 \\
$\%$ of total sample & $90.7 \%$ & $9.3 \%$ & $100 \%$ & $88.4 \%$ & $10.4 \%$ & $1.2 \%$ & $100 \%$ \\
\hline
\end{tabular}

Table 1c Interval between maintenance visits during previous year in cases and controls

\begin{tabular}{clllll}
\hline & \multicolumn{5}{c}{ Interval between maintenance visits } \\
\cline { 2 - 6 } & $1-3$ months & $4-5$ months & 6 months & $>6$ months & Total \\
\hline Cases, No. & 22 & 52 & 87 & 109 & 270 \\
\% of cases & $8.1 \%$ & $19.3 \%$ & $32.2 \%$ & $40.4 \%$ & $100 \%$ \\
$\%$ of total sample & $1.6 \%$ & $3.9 \%$ & $6.4 \%$ & $8.1 \%$ & $20 \%$ \\
Controls, No. & 32 & 109 & 418 & 521 & 1,080 \\
$\%$ of controls & $3.0 \%$ & $10.1 \%$ & $38.7 \%$ & $48.2 \%$ & $100 \%$ \\
$\%$ of total sample & $2.4 \%$ & $8.1 \%$ & $31.0 \%$ & $38.6 \%$ & $80 \%$ \\
Total, No. & 54 & 161 & 505 & 630 & 1,350 \\
$\%$ of total sample & $4.0 \%$ & $11.9 \%$ & $37.4 \%$ & $46.7 \%$ & $100 \%$ \\
\hline
\end{tabular}

pathology of approximately 5.0. Patients with BL around the middle and apical thirds of implants had ORs for peri-implant pathology of 8.4 and 8.6, respectively, and patients with a shorter IMV during the previous year had ORs of 2.9 (interval, 1-3 months) and 2.1 (4-5 months) (Table 3).

AFS indicated that the number of cases with periimplant pathology could be decreased if exposures to the risk indicators DP, B, PIP $>4 \mathrm{~mm}, \mathrm{BL}$ (middle and apical thirds of the implant), and FVM (interval, 1-3 months and 3-5 months) were reduced (Table 3).

\section{Discussion}

The presence of DP, B, PIP $>4 \mathrm{~mm}$, and BL around the middle or apical thirds of implants significantly differed between cases and controls, and these variables are thus risk indicators for the incidence of peri-implant pathology.

DP has known deleterious effects and is therefore considered a principal risk factor (52). Pontoriero et al. (2) attempted to replicate the conditions of an experimental gingivitis model in their study of 20 partially edentulous patients who were treated with implants and subsequently refrained from oral hygiene for a period of 
Table 2 Inferential statistics for dental plaque, bleeding index, peri-implant pockets $>4 \mathrm{~mm}$, bone level, and interval between maintenance visits

\begin{tabular}{|c|c|c|c|c|}
\hline & $\begin{array}{l}\text { Cases, relative frequency } \\
\text { ( } 95 \% \text { CI proportion) }\end{array}$ & $\begin{array}{l}\text { Controls, relative frequency } \\
\text { ( } 95 \% \text { CI proportion) }\end{array}$ & $\begin{array}{l}\text { Absolute frequency } \\
\text { (95\% CI proportion) }\end{array}$ & $P$ value \\
\hline \multicolumn{5}{|c|}{ Presence of dental plaque around implant } \\
\hline Yes & $73 / 270=0.27(0.22 ; 0.32)$ & $72 / 1,080=0.07(0.05 ; 0.08)$ & $145 / 1,350=0.11(0.09 ; 0.12)$ & \multirow{2}{*}{0.000} \\
\hline No & $197 / 270=0.73(0.68 ; 0.78)$ & $1,008 / 1,080=0.93(0.92 ; 0.95)$ & $1,205 / 1,350=0.89(0.88 ; 0.91)$ & \\
\hline \multicolumn{5}{|c|}{ Presence of bleeding around implant } \\
\hline Yes & $70 / 270=0.26(0.21 ; 0.31)$ & $71 / 1,080=0.07(0.05 ; 0.08)$ & $141 / 1,350=0.10(0.09 ; 0.12)$ & \multirow[t]{2}{*}{0.000} \\
\hline No & $200 / 270=0.74(0.69 ; 0.79)$ & $1,009 / 1,080=0.93(0.92 ; 0.95)$ & $1,209 / 1,350=0.90(0.88 ; 0.91)$ & \\
\hline \multicolumn{5}{|c|}{ Presence of peri-implant pockets $>4 \mathrm{~mm}$} \\
\hline Yes & $93 / 270=0.34(0.29 ; 0.40)$ & $32 / 1,080=0.03(0.02 ; 0.04)$ & $125 / 1,350=0.09(0.08 ; 0.11)$ & \multirow[t]{2}{*}{0.000} \\
\hline No & $177 / 270=0.66(0.60 ; 0.71)$ & $1,048 / 1,080=0.97(0.96 ; 0.98)$ & $1,225 / 1,350=0.91(0.89 ; 0.92)$ & \\
\hline \multicolumn{5}{|c|}{ Bone level } \\
\hline $\mathrm{c} 1 / 3^{*}$ & $176 / 270=0.65(0.60 ; 0.71)$ & $1,017 / 1,080=0.94(0.93 ; 0.96)$ & $1,193 / 1,350=0.88(0.87 ; 0.90)$ & \multirow[t]{3}{*}{0.000} \\
\hline $\mathrm{m} 1 / 3^{\pi}$ & $85 / 270=0.31(0.26 ; 0.37)$ & $56 / 1,080=0.05(0.04 ; 0.07)$ & $141 / 1,350=0.10(0.09 ; 0.12)$ & \\
\hline $\mathrm{a} 1 / 3^{*}$ & $9 / 270=0.03(0.01 ; 0.05)$ & $7 / 1,080=0.01(0.00 ; 0.01)$ & $16 / 1,350=0.01(0.01 ; 0.02)$ & \\
\hline \multicolumn{5}{|c|}{ Interval between maintenance visits } \\
\hline $1-3 \mathrm{~m}^{\alpha}$ & $22 / 270=0.08(0.05 ; 0.11)$ & $32 / 1,080=0.03(0.02 ; 0.04)$ & $54 / 1,350=0.04(0.03 ; 0.05)$ & \multirow[t]{4}{*}{0.000} \\
\hline $4-5 \mathrm{~m}^{\varphi}$ & $52 / 270=0.19(0.15 ; 0.24)$ & $109 / 1,080=0.10(0.08 ; 0.12)$ & $161 / 1,350=0.12(0.10 ; 0.14)$ & \\
\hline $6 \mathrm{~m}^{\psi}$ & $87 / 270=0.32(0.27 ; 0.38)$ & $418 / 1,080=0.39(0.36 ; 0.42)$ & $505 / 1,350=0.37(0.35 ; 0.40)$ & \\
\hline$>6 \mathrm{~m}^{\sigma}$ & $109 / 270=0.40(0.35 ; 0.46)$ & $521 / 1,080=0.48(0.45 ; 0.51)$ & $630 / 1,350=0.47(0.44 ; 0.49)$ & \\
\hline
\end{tabular}

* c1/3: coronal third of implant; ${ }^{\pi} \mathrm{ml} / 3$ : middle third of implant; ${ }^{*} \mathrm{a} 1 / 3$ : apical third of implant; ${ }^{\alpha} 1-3 \mathrm{~m}: 1-3 \mathrm{months} ;{ }^{\varphi} 4-5 \mathrm{~m}: 4-5 \mathrm{months} ;{ }^{\psi} 6 \mathrm{~m}$ : 6 months; ø>6 m: $>6$ months

Table 3 Crude odds ratios (ORs) and attributable fractions for peri-implant pathology associated with dental plaque, bleeding, peri-implant pockets $>4 \mathrm{~mm}$, bone level, and interval between maintenance visits during the previous year

\begin{tabular}{llccc}
\hline & & OR & $95 \%$ Confidence interval & Attributable fraction \\
\hline Presence of dental plaque around implant & Absent & 0.19 & {$[0.14 ; 0.28]$} & 0.81 \\
& Present & 5.19 & {$[3.62 ; 7.43]$} & 0.80 \\
Presence of bleeding around implant & Absent & 0.20 & {$[0.14 ; 0.29]$} & 0.94 \\
& Present & 4.97 & {$[3.46 ; 7.15]$} & 0.88 \\
Presence of peri-implant pockets $>4 \mathrm{~mm}$ & Absent & 0.06 & {$[0.04 ; 0.09]$} & 0.88 \\
& Present & 17.21 & {$[11.17 ; 26.51]$} & 0.66 \\
Bone level & Coronal $1 / 3$ & 0.12 & {$[0.08 ; 0.17]$} & 0.53 \\
& Middle $1 / 3$ & 8.40 & {$[5.79 ; 12.19]$} & {$[3.15 ; 23.33]$} \\
Interval between maintenance visits & Apical $1 / 3$ & 8.57 & {$[1.66 ; 5.09]$} & {$[1.48 ; 3.05]$} \\
during the previous year & $1-3$ months & 2.91 & {$[0.57 ; 1.00]$} & \\
& $4-5$ months & 2.13 & $0.55 ; 0.95]$ & \\
\hline
\end{tabular}

3 weeks. They observed an increase in mucositis severity, including inflammation of the soft tissues and an increase of $\pm 1 \mathrm{~mm}$ in peri-implant pockets. These findings confirm the causal relation between DP accumulation and periimplant health, i.e., the classical pathway of peri-implant pathology.

The effect of $\mathrm{B}$ on the incidence of peri-implant pathology is likely due to its association with DP and consequent PIP. This represents the classical clinical manifestation of peri-implant pathology, namely, DP accumulation, followed by B resulting from gingival inflammation and PIP formation. This finding was previously reported $(2,53,54)$. The type of mucosa (keratinized vs. non-keratinized) might also be important in disease 
incidence and development; however, our study did not investigate mucosa type, and thus the effect of this variable is unknown.

Presence of PIP $>4 \mathrm{~mm}$ was more frequent in patients with peri-implant pathology. In our study, a $0.25-\mathrm{N}$ calibrated plastic probe was used to measure PIP, in conjunction with routine tri-annual calibrations between clinicians, which aimed to increase measurement reproducibility and accuracy (55). This diagnostic tool has high sensitivity for monitoring peri-implant conditions, despite the number of variables that affect such measurements (28). As a result of inflammation, a peri-implant sulcus may develop until a pocket is formed, and this increase should be regarded as a sign of peri-implant pathology, as noted in previous reports $(30,31)$. The microbiological characteristics of peri-implant pockets are comparable to those of periodontal pockets: both are associated with colonization of gram-negative bacteria (32). Therefore, evaluation for PIP is important for identifying peri-implant pathology. Nevertheless, increased probing depths around implants may not indicate the presence of pathology (33); thus, probing depth should be used in conjunction with other diagnostic tools (34).

The inclusion of $\mathrm{BL}$ as a possible risk indicator for peri-implant pathology is a subject of discussion. If BL in cases reflects pathology (due to the presence of marginal bone resorption), $\mathrm{BL}$ in the controls (i.e., in the absence of PIP $>4 \mathrm{~mm}$, B, or marginal bone resorption) refers to the location of bone around a given implant and is influenced by bone quantity and quality available at the time of treatment, by implant length, and by physiological marginal bone resorption during follow-up (22). This means that $\mathrm{BL}$ around a given implant represents the end result, which is due to bone loss (in the presence of periimplant pathology) or other non-pathological conditions. A BL around the middle or apical third of implants was identified as a risk indicator $(\mathrm{OR}=8.4$ and 8.6 , respectively). As mentioned above, this can represent either a symptom or a cause of disease: as BL progresses toward the implant apex, implant support decreases, thereby reducing stability (26) and the ability to support occlusal forces, which increases the probability of disease due to biomechanical factors. This is particularly important when BL is such that more than two or three threads of the implant are exposed (the area of engagement of the abutment screw), as such conditions increase the risk of implant fracture due to bending overload (56).

Our finding that a shorter IMV is a risk factor should be interpreted with caution. A possible explanation for this finding is that patients with shorter IMVs were considered to be at high risk at the start of therapy (e.g., patients with a history of periodontitis, mucositis, smokers, and those with low compliance to oral hygiene instructions) and were therefore scheduled for more frequent followup. This possibility was not investigated in this study, and the question remains open. Another possible explanation is the strong possibility of a confounder effect from DP and smoking. Among the 270 patients with peri-implant pathology, 196 had an IMV of $\geq 6$ months during the previous year. Among these patients, $75(38 \%)$ had DP accumulation. In contrast, among the 74 patients with peri-implant pathology and an IMV of $<6$ months during the previous year, $38(51 \%)$ had DP accumulation. Similarly, the proportion of smokers was $14 \%$ higher among cases than among controls ( $38.5 \%$ vs. $24 \%$, respectively), which was a significant difference. In consideration of these results and the important effects of DP and smoking on outcomes of dental implant treatment, this confounder effect is likely the main reason that shorter IMVs were found to be a risk indicator in our study. If so, the odds ratio for peri-implant pathology associated with shorter IMV is probably an overestimate. We do not mean to suggest that maintenance has a deleterious effect on implant outcome. Rather, other variables, such as good oral hygiene, likely have a stronger effect than implant maintenance on IMV. A recent prospective study (52) confirmed the importance of preventive maintenance: the incidence of peri-implantitis at 5 years of followup was $25 \%$ higher among patients without preventive maintenance than in those who had received preventive maintenance.

Reduction of exposures to DP, B, PIP, and BL could reduce the number of exposed individuals by at least $80 \%$. This suggests that prevention of DP accumulation in the present population could potentially result in an $81 \%$ decrease in the number of patients who develop disease (51). Moreover, in the clinical setting, one should consider the cumulative effect of reduced exposure to DP on the overall number of cases, as reduced exposure to DP would directly influence exposures to B, PIP, and $\mathrm{BL}$, thus ceasing the chain of events leading to disease. $\mathrm{B}$ would be prevented because it occurs in response to plaque accumulation. PIP would potentially be partially prevented due to the absence of DP accumulation and consequent prevention of mucositis. Lower BL due to marginal bone resorption would also be substantially prevented. This further highlights the importance of controlling DP accumulation around implants and the consequent importance of maintenance.

This study had the following limitations: a retrospective design, lack of control for possible confounders, and lack of control for the presence of other variables such as 
systemic compromise ( $38 \%$ of cases and $43 \%$ of controls) and smoking habit (38\% of cases and $24 \%$ of controls). The effect of variables on the incidence of peri-implant pathology should be investigated in prospective studies using multivariable analysis to control for confounding relationships between variables and the presence of other variables of interest.

In conclusion, we found that DP, B, PIP $>4 \mathrm{~mm}, \mathrm{BL}$ in the middle or apical third of implants, and shorter IMVs were risk indicators for peri-implant pathology. Our findings suggest that DP has a direct effect on the other clinical characteristics investigated in this study. Reduced exposure to these variables could substantially reduce the number of affected individuals.

\section{Acknowledgments}

This study was supported by a grant from Nobel Biocare Services AG (grant 2012-1126). Professor Maló is currently a consultant for Nobel Biocare.

\section{References}

1. Albrektsson T, Isidor F (1994) Consensus report of session IV. In: Proceedings of the first European workshop on periodontology 1994, Lang NP, Karring T eds, Quintessence, London, 365-369.

2. Pontoriero R, Tonelli MP, Carnevale G, Mombelli A, Nyman SR, Lang NP (1994) Experimentally induced peri-implant mucositis. A clinical study in humans. Clin Oral Implants Res 5, 254-259.

3. Mombelli A (1999) In vitro models of biological responses to implant microbiological models. Adv Dent Res 13, 67-72.

4. Meffert RM (1990) Research in implantology at Louisiana State University School of Dentistry. Int J Oral Implantol 6, 15-21.

5. el Askary AS, Meffert RM, Griffin T (1998) Why do dental implants fail? Part II. Implant Dent 8, 265-276.

6. Ayangco L, Sheridan PJ (2001) Development and treatment of retrograde peri-implantitis involving a site with a history of failed endodontic and apicoectomy procedures: a series of reports. Int J Oral Maxillofac Implants 16, 412-417.

7. Esposito M, Hirsch JM, Lekholm U, Thomsen P (1998) Biological factors contributing to failures of osseointegrated oral implants. (II). Etiopathogenesis. Eur J Oral Sci 106, 721-764.

8. Zitzmann NU, Berglundh T (2008) Definition and prevalence of peri-implant diseases. J Clin Periodontol 35, Suppl, 286-291.

9. Haas R, Haimböck W, Mailath G, Watzek G (1996) The relationship of smoking on peri-implant tissue: a retrospective study. J Prosthet Dent 76, 592-596.

10. Rutar A, Lang NP, Buser D, Bürgin W, Mombelli A (2001) Retrospective assessment of clinical and microbiological factors affecting periimplant tissue conditions. Clin Oral
Implants Res 12, 189-195.

11. Rosenberg ES, Cho SC, Elian N, Jalbout ZN, Froum S, Evian CI (2004) A comparison of characteristics of implant failure and survival in periodontally compromised and periodontally healthy patients: a clinical report. Int J Oral Maxillofac Implants 19, 873-879.

12. Karoussis IK, Müller S, Salvi GE, Heitz-Mayfield LJ, Brägger U, Lang NP (2004) Association between periodontal and peri-implant conditions: a 10-year prospective study. Clin Oral Implants Res 15, 1-7.

13. Quirynen M, Vogels R, Alsaadi G, Naert I, Jacobs R, van Steenberghe D (2005) Predisposing conditions for retrograde peri-implantitis, and treatment suggestions. Clin Oral Implants Res 16, 599-608.

14. Roos-Jansäker AM, Renvert H, Lindahl C, Renvert S (2006) Nine- to fourteen-year follow-up of implant treatment. Part III: factors associated with peri-implant lesions. J Clin Periodontol 33, 296-301.

15. Ferreira SD, Silva GL, Cortelli JR, Costa JE, Costa FO (2006) Prevalence and risk variables for peri-implant disease in Brazilian subjects. J Clin Periodontol 33, 929-935.

16. Máximo MB, de Mendonça AC, Alves JF, Cortelli SC, Peruzzo DC, Duarte PM (2008) Peri-implant diseases may be associated with increased time loading and generalized periodontal bone loss: preliminary results. J Oral Implantol 34, 268-273.

17. Serino G, Ström C (2009) Peri-implantitis in partially edentulous patients: association with inadequate plaque control. Clin Oral Implants Res 20, 169-174.

18. Zhou W, Han C, Li D, Li Y, Song Y, Zhao Y (2009) Endondontic treatment of teeth induces retrograde peri-implantitis. Clin Oral Implant Res 20, 1326-1332.

19. Aloufi F, Bissada N, Ficara A, Faddoul F, Al-Zahrani MS (2009) Clinical assessment of peri-implant tissues in patients with varying severity of chronic periodontitis. Clin Implant Dent Relat Res 11, 37-40.

20. de Araújo Nobre MA, Maló P (2014) The influence of rehabilitation characteristics in the incidence of peri-implant pathology: a case-control study. J Prosthodont 23, 21-30.

21. Buser D, Weber HP, Lang NP (1990) Tissue integration of non-submerged implants. 1-year results of a prospective study with 100 ITI hollow-cylinder and hollow-screw implants. Clin Oral Implants Res 1, 33-40.

22. Albrektsson T, Zarb G, Worthington P, Eriksson AR (1986) The long-term efficacy of currently used dental implants: a review and proposed criteria of success. Int J Oral Maxillofac Implants 1, 11-25.

23. Quirynen M, Naert I, van Steenberghe D, Schepers E, Calberson L, Theuniers G et al. (1991) The cumulative failure rate of the Brånemark system in the overdenture, the fixed partial, and the fixed full prostheses design: a prospective study on 1273 fixtures. J Head Neck Pathol 10, 43-53.

24. Quirynen M, Naert I, van Steenberghe D, Dekeyser C, Callens A (1992) Periodontal aspects of osseointegrated fixtures supporting a partial bridge. An up to 6-years retrospective 
study. J Clin Periodontol 19, 118-126.

25. Lekholm U, van Steenberghe D, Herrmann I, Bolender C, Folmer T, Gunne J et al. (1994) Osseointegrated implants in the treatment of partially edentulous jaws: a prospective 5-year multicenter study. Int J Oral Maxillofac Implants 9, 627-635.

26. Chong L, Khocht A, Suzuki JB, Gaughan J (2009) Effect of implant design on initial stability of tapered implants. J Oral Implantol 35, 130-135.

27. Gerber JA, Tan WC, Balmer TE, Salvi GE, Lang NP (2009) Bleeding on probing and pocket probing depth in relation to probing pressure and mucosal health around oral implants. Clin Oral Implants Res 20, 75-78.

28. Salvi GE, Lang NP (2004) Diagnostic parameters for monitoring peri-implant conditions. Int J Oral Maxillofac Implants 19, S116-127.

29. Mombelli A, Mühle T, Brägger U, Lang NP, Bürgin WB (1997) Comparison of periodontal and peri-implant probing by depth-force pattern analysis. Clin Oral Implants Res 8, 448-455.

30. Mombelli A, Lang NP (1994) Clinical parameters for the evaluation of dental implants. Periodontol 2000 4, 81-86.

31. Lang NP, Berglundh T, Heitz-Mayfield LJ, Pjetursson BE, Salvi GE, Sanz M (2004) Consensus statements and recommended clinical procedures regarding implant survival and complications. Int J Oral Maxillofac Implants 19, S150-154.

32. Quirynen M, De Soete M, van Steenberghe D (2002) Infectious risks for oral implants: a review of the literature. Clin Oral Implants Res 13, 1-19.

33. Kan JY, Rungcharassaeng K, Umezu K, Kois JC (2003) Dimensions of peri-implant mucosa: an evaluation of maxillary anterior single implants in humans. J Periodontol 74, 557-562.

34. Meyle J (2012) Mechanical, chemical and laser treatments of the implant surface in the presence of marginal bone loss around implants. Eur J Oral Implantol 5, S71-81.

35. Esposito M, Hirsch JM, Lekholm U, Thomsen P (1998) Biological factors contributing to failures of osseointegrated oral implants. (I). Success criteria and epidemiology. Eur J Oral Sci 106, 527-551.

36. Nakou M, Mikx FH, Oosterwaal PJ, Kruijsen JC (1987) Early microbial colonization of permucosal implants in edentulous patients. J Dent Res 66, 1654-1657.

37. Zitzmann NU, Berglundh T, Marinello CP, Lindhe J (2001) Experimental peri-implant mucositis in man. J Clin Periodontol 28, 517-523.

38. Lang NP, Mombelli A, Tonetti MS, Brägger U, Hämmerle CH (1997) Clinical trials on therapies for peri-implant infections. Ann Periodontol 2, 343-356.

39. Abrahamsson I, Berglundh T, Lindhe J (1998) Soft tissue response to plaque formation at different implant systems. A comparative study in the dog. Clin Oral Implants Res 9, 73-79.

40. Lindquist LW, Carlsson GE, Jemt T (1996) A prospective 15-year follow-up study of mandibular fixed prostheses supported by osseointegrated implants. Clinical results and marginal bone loss. Clin Oral Implants Res 7, 329-336.

41. Grusovin MG, Coulthard P, Jourabchian E, Worthington HV, Esposito MA (2008) Interventions for replacing missing teeth: maintaining and recovering soft tissue health around dental implants. Cochrane Database Syst Rev, CD003069.

42. Kozlovsky A, Mozes O, Nemcovsky CE, Artzi Z (2003) Differential diagnosis and treatment strategies for periimplant diseases. Refuat Hapeh Vehashinayim 20, 30-41.

43. Yeung SC (2008) Biological basis for soft tissue management in implant dentistry. Aust Dent J 53, S39-42.

44. Schou S (2008) Implant treatment in periodontitis-susceptible patients: a systematic review. J Oral Rehabil 35, S9-22.

45. Kourtis SG, Sotiriadou S, Voliotis S, Challas A (2004) Private practice results of dental implants. Part I: survival and evaluation of risk factors--Part II: surgical and prosthetic complications. Implant Dent 13, 373-385.

46. von Elm E, Altman DG, Egger M, Pocock SJ, Gøtzsche PC, Vandenbroucke JP (2007) The strengthening the reporting of observational studies in epidemiology (STROBE) statement: guidelines for reporting observational studies. Epidemiology $18,800-804$.

47. De Araújo Nobre M, Capelas C, Alves A, Almeida T, Carvalho R, Antunes E et al. (2006) Non-surgical treatment of peri-implant pathology. Int J Dent Hyg 4, 84-90.

48. Fiorellini JP, Weber HP (1994) Clinical trials on the prognosis of dental implants. Periodontol 2000 4, 98-108.

49. Moy PK, Medina D, Shetty V, Aghaloo TL (2005) Dental implant failure rates and associated risk factors. Int J Oral Maxillofac Implants 20, 569-577.

50. Tonetti MS (1999) Determination of the success and failure of root-form osseointegrated dental implants. Adv Dent Res 13, 173-180.

51. Rothman KJ, Greenland S (1998) Measures of effect and measures of association. In: Modern epidemiology 1998, 2nd ed, Lippincott-Raven, Philadelphia, 53-55.

52. Esposito M, Grusovin MG, Worthington HV (2012) Interventions for replacing missing teeth: treatment of peri-implantitis. Cochrane Database Syst, CD004970.

53. Kaptein ML, De Lange GL, Blijdorp PA (1999) Peri-implant tissue health in reconstructed atrophic maxillae--report of 88 patients and 470 implants. J Oral Rehabil 26, 464-474.

54. Costa FO, Takenaka-Martinez S, Cota LO, Ferreira SD, Silva GL, Costa JE (2012) Peri-implant disease in subjects with and without preventive maintenance: a 5-year follow-up. J Clin Periodontol 39, 173-181.

55. Christensen MM, Joss A, Lang NP (1997) Reproducibility of automated periodontal probing around teeth and osseointegrated oral implants. Clin Oral Implants Res 8, 455-464.

56. Rangert B, Krogh PH, Langer B, Van Roekel N (1995) Bending overload and implant fracture: a retrospective clinical analysis. Int J Oral Maxillofac Implants 10, 326-334. 